\title{
Rolling Direction Dependent Diffusion Coefficients of Hydrogen in Ferritic Steel by SDCM Charging and SKP Probing
}

\author{
Gabriela SCHIMO, ${ }^{1,2)}$ Wolfgang BURGSTALLER ${ }^{2,3)}$ and Achim Walter HASSEL ${ }^{1,2,3) *}$ \\ 1) CEST Competence Centre for Electrochemical Surface Technology, Viktor-Kaplan-Str. 2, 2700 Wiener Neustadt, Austria. \\ 2) Institute for Chemical Technology of Inorganic Materials, Johannes Kepler University Linz, Altenberger Str. 69, 4040 Linz, \\ Austria. $\quad 3$ 3) Christian Doppler Laboratory for Combinatorial Oxide Chemistry, at the Institute for Chemical Technology of \\ Inorganic Materials, Johannes Kepler University Linz, Altenberger Str. 69, 4040 Linz, Austria.
}

(Received on July 14, 2015; accepted on January 12, 2016; J-STAGE Advance published date: February $25,2016)$

\begin{abstract}
Surface potential mapping of ferritic steel loaded with hydrogen through scanning droplet cell microscopy was performed with scanning Kelvin probe showing a drop in measured contact potential difference on hydrogen loaded spot. Equipotential areas were defined and used for determination of hydrogen diffusion coefficient parallel and orthogonal to rolling direction, resulting in values of $1.75 \times 10^{-7} \mathrm{~cm}^{2} \mathrm{~s}^{-1}$ and $3.51 \times 10^{-7} \mathrm{~cm}^{2} \mathrm{~s}^{-1}$, respectively. By controlling atmosphere composition and humidity during consecutive Kelvin probe measurements, the influence of oxygen concentration on the hydrogen discharging process was investigated, revealing interaction between surface oxides and hydrogen.
\end{abstract}

KEY WORDS: hydrogen detection; scanning Kelvin probe; scanning droplet cell microscopy; hydrogen diffusion coefficient; ferritic steel.

\section{Introduction}

Hydrogen detection in metals is a research field of growing importance, especially in the last decades since hydrogen is increasingly used as energy carrier and hydrogen-embrittlement related failures have emerged as serious problem for the steel industry. Numerous techniques have been developed in order to study hydrogen diffusion in metals and enabling determination of the hydrogen diffusion coefficient, amount of diffusible hydrogen as well as trapping effects. Thermal desorption spectroscopy ${ }^{1-4)}$ and electrochemical methods ${ }^{1,5-8)}$ constitute a large part of these techniques. However, the number of techniques capable of visualizing diffusible hydrogen and its distribution in a metal sample is very limited. Important examples are hydrogen microprint technique, ${ }^{9-13)}$ silver decoration ${ }^{14,15)}$ and secondary ion mass spectrometry. ${ }^{16-19)}$ A relatively new method of visualizing hydrogen in steel is the spatially resolved detection via scanning Kelvin probe (SKP), which was already successfully applied for determination of hydrogen in palladium, ${ }^{20-22)}$ iron $^{23)}$ and steel, ${ }^{20,22,24,25)}$ as hydrogen causes a change in work function, detected by SKP. Advantages of this technique are arising from the very sensitive, non-destructive measurement principle, the possibility to investigate surface processes as well as the possibility to link the measured work function or rather contact potential difference (CPD) with an electrochemical potential. ${ }^{26)}$ In this manner, influence of microstructural defects in steel,

* Corresponding author: E-mail: achimwalter.hassel@jku.at DOI: http://dx.doi.org/10.2355/isijinternational.ISIJINT-2015-382 e.g. induced by cold rolling process, on the diffusional transport of hydrogen through the material can be studied by SKP. By evaluation of surface potential maps obtained by SKP measurements, hydrogen diffusion coefficient can be simultaneously determined parallel and perpendicular to rolling direction. Furthermore, interaction of oxygen from atmosphere and hydrogen included in the steel sample along with surface oxide formation and resulting composition in terms of $\mathrm{Fe}^{2+} / \mathrm{Fe}^{3+}$ ratio is tracked. In this work, the effect of rolling direction on the hydrogen diffusion coefficient and influence of oxygen content on re-formation of surface oxides was studied for ferritic steel.

\section{Experimental}

In this work, a $30 \times 50 \mathrm{~mm}^{2}$ sized cold-rolled Fe- $0.04 \mathrm{C}$ $0.18 \mathrm{Mn}-0.01 \mathrm{P}-0.011 \mathrm{~S}$ steel (wt\%) with a final thickness of $1.06 \mathrm{~mm}$ was used. The sample was degreased and cleaned with isopropanol, ethanol and water in ultrasonic bath prior to use. Electrochemical hydrogen loading was performed at room temperature on a circular spot ( $3.5 \mathrm{~mm}$ diameter) with a $3 \mathrm{D}$ printed electrochemical cell ${ }^{27)}$ offering an U-shaped electrolyte flow channel and a gold counter electrode mounted parallel to the sample as depicted in Fig. 1. The distance between working electrode (sample) and counter electrode was $1.5 \mathrm{~mm}$. The electrolyte was forced to pass by the electrodes at a pumping speed of $3 \mathrm{~cm}^{3} \mathrm{~s}^{-1}$, which allowed an effective removal of gas bubbles resulting in an homogeneous hydrogen charging of the treated spot. As electrolyte $0.1 \mathrm{M} \mathrm{NaOH}$ solution with addition of $0.2 \mathrm{~g} \mathrm{l}^{-1}$ thiourea as hydrogen recombination inhibitor was utilized. 
Galvanostatic cathodic polarization at a current density of $10 \mathrm{~mA} \mathrm{~cm}{ }^{-2}$ was maintained for $3.5 \mathrm{~h}$, which is sufficient to ensure that hydrogen transfer rate is the same throughout the membrane. The choice of charging time was confirmed in a previously performed electrochemical hydrogen permeation experiment according to Devanathan and Stachurski, ${ }^{5)}$ which showed reaching of the steady-state after $3 \mathrm{~h}$. From this experiment, the hydrogen diffusion coefficient $(D)$ was also determined via time-lag method giving a value of $2.4 \times 10^{-7} \mathrm{~cm}^{2} \mathrm{~s}^{-1}$, which will be later used in this work as reference. Directly after finalizing hydrogen loading $\left(t_{0}\right)$, the hydrogen charged spot was marked with a water-proof marker and the sample was rinsed with deionized water, dried in nitrogen gas stream and transferred into the SKP chamber. For the measurements an in house developed SKP with essential parts from Wicinski \& Wicinski GbR equipped with $\mathrm{Cr}-\mathrm{Ni}$ probe tip (300 $\mu \mathrm{m}$ diameter) was used.

\section{Results and Discussion}

The measurement atmosphere was adjusted to $1.2 \pm 0.5 \%$ relative humidity $(\mathrm{rH})$ and below 1 vol $\% \mathrm{O}_{2}$ by purging the SKP chamber with pure nitrogen. An area of $8 \times 8 \mathrm{~mm}^{2}$ including the hydrogen charged spot was scanned for $45 \mathrm{~h}$, corresponding to 33 consecutive scans. After 20 surface scans $\left(t_{0}+25 \mathrm{~h}\right)$, the chamber atmosphere composition was altered to $20 \mathrm{vol} \% \mathrm{O}_{2}$ at $4 \% \mathrm{rH}$. Selected results of surface scans $\left(t_{0}+1,5\right.$ and $\left.10 \mathrm{~h}\right)$ are presented in Fig. 2. For purpose of comparability, a surface scan of the hydrogen-free sample was performed under both atmospheric conditions, revealing a stable potential of $0.184 \pm 0.008 \mathrm{~V}$ (SHE) over the entire scanned surface. In contrast, scans conducted after

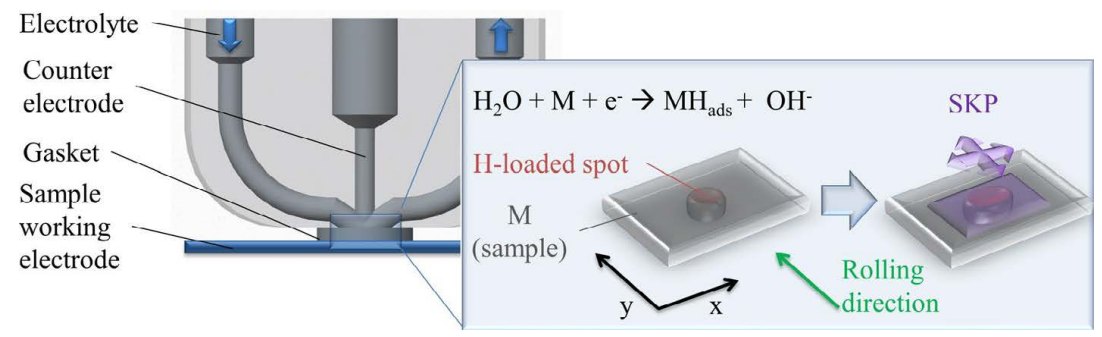

Fig. 1. Schematic depicting hydrogen loading of steel sample with a 3D printed electrochemical flow cell (left) and subsequent measurement procedure including scanning Kelvin probe detection of hydrogen (right). (Online version in color.)



Fig. 2. Representative SKP potential maps of hydrogen charged surface of ferritic steel after 1,5 and $10 \mathrm{~h}$ as well as uncharged surface with equipotential areas marked for contact potential difference (CPD) values of $-0.2,-0.1$ and $0.0 \mathrm{~V}$ (SHE). (Online version in color.) 
hydrogen loading clearly show the hydrogen loaded spot, which is characterized by a sharp drop in measured CPD as compared to the initial value. This drop was already reported in literature ${ }^{22,23,25)}$ and explained profoundly by changes in the band structure of natural oxides on the surface of the steel. $^{28-30)}$ After electrochemical hydrogen loading and necessary cathodic polarization of the steel sample, the initial surface oxides are completely reduced to iron affecting the Fermi level alignment. As recorded CPD is, due to calibration on $\mathrm{Cu} / \mathrm{Cu}^{2+}$ - electrochemical system, directly linked to electrochemical potentials, ${ }^{26)}$ the explanation for a decrease of measured CPD can be easily given by Nernst equation. For the uncharged specimen with native oxide layer, the CPD is governed by following reaction:

$$
C P D_{\text {uncharged }} \equiv E_{\text {uncharged }}=E_{F e^{2+} / F e^{3+}}^{0}-\frac{R T}{F} \ln \frac{a_{F e^{2+}}}{a_{F e^{3+}}} \ldots
$$

With $E^{0}$ describing the standard electrode potential, $R$ the ideal gas constant, $T$ the temperature, $F$ the Faraday constant and $a$ the activities of both reduced and oxidized species.

Immediately after hydrogen loading the steel sample is transferred to the SKP measurement chamber, which is flushed with dry nitrogen. Therefore, it can be assumed that only a thin oxide layer has already formed before the very first SKP measurement cycle. By taking into account the contribution of $\mathrm{Fe} / \mathrm{Fe}^{2+}$ redox couple, exhibiting a more negative $E^{0}$ value compared to $\mathrm{Fe}^{2+} / \mathrm{Fe}^{3+}$, the lowered CPD values can be explained.

Based on the potential maps, equipotential lines were defined for $-0.2,-0.1,0.0,0.1,0.2,0.3$ and $0.4 \mathrm{~V}$ (SHE). These equipotential lines describe, in turn, areas of equal potential and thus equal hydrogen concentration. In this manner, the equipotential area at $-0.2 \mathrm{~V}$ represents the region with the highest hydrogen concentration, whereas almost no hydrogen is located in the area with $0.2 \mathrm{~V}$, close to the initial potential. Areas with potentials above the initial value of $0.184 \mathrm{~V}$ circular surrounding the hydrogen containing region originate from marking of the measurement spot. In order to obtain information of hydrogen diffusion

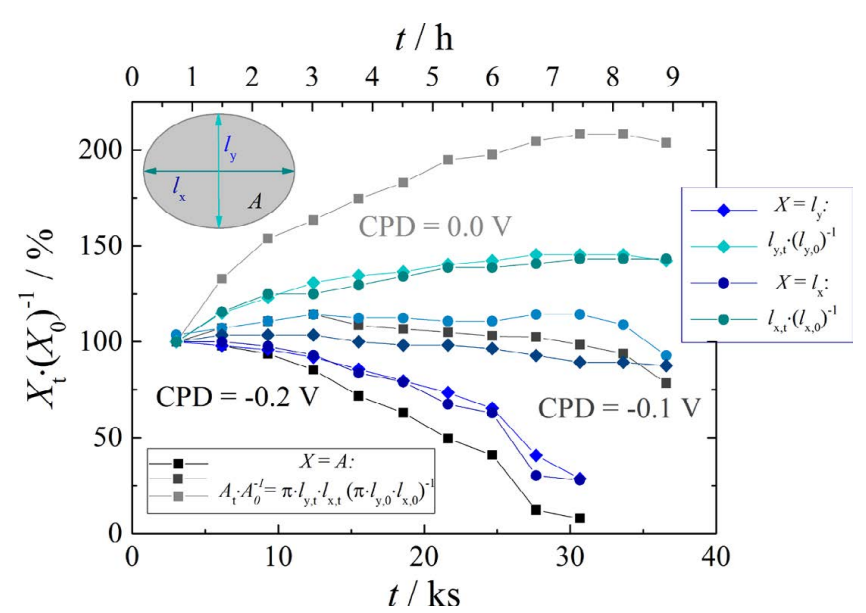

Fig. 3. Evaluation of elliptically shaped equipotential areas at $-0.2,-0.1$ and $0.0 \mathrm{~V}$ (SHE) including length of major (1x) and minor (ly) axis as well as calculated area (Ax, Ay), each of them divided by their initial value at to. (Online version in color.) beyond the limits of the loaded area, further data evaluation will focus on the equipotential areas with lowest potentials. Equipotential area of $-0.2 \mathrm{~V}$ is of almost circular shape and shrinks constantly before it vanishes after $7.5 \mathrm{~h}$. The shape of the equipotential area of $-0.1 \mathrm{~V}$ is also almost circular, but in contrast to the $0.2 \mathrm{~V}$-level it is not subjected to shrinkage, it rather keeps more or less its initial dimension. Stepping to the subsequent equipotential area at $0.0 \mathrm{~V}$, the behavior changes once more as it is steadily increasing. Based on these findings, which are summarized in Fig. 3, it can be concluded that the area with the lowest potential of the above described acts as source for diffusible hydrogen, whereas dimensions of the area at $0.0 \mathrm{~V}$ represent the actual movement of hydrogen further into the material. The area in-between those two at $-0.1 \mathrm{~V}$ behaves like a buffer and is therefore remaining at almost constant size. However, it has to be noted that these conclusions are only valid for the regarded time interval of the overall measurement. After the equipotential area of $-0.2 \mathrm{~V}$ has disappeared, equipotential area of $-0.1 \mathrm{~V}$ will become the one prone to shrink as it will deliver hydrogen to the subsequent equipotential area. This procedure will continue until the potential has reached its initial value.

For the determination of the hydrogen diffusion coefficient from data obtained in the first $9 \mathrm{~h}$ after finishing hydrogen loading, it is most convenient to focus on the equipotential area of $0.0 \mathrm{~V}$ as it is, regarded in direction towards positive potentials, the first of the defined areas, which is characterized by an increase in size. This means that its dimensions in $x$ - and $y$-direction, defined by lengths of minor and major axis of the ellipse used for approximate description of the equipotential area, can be viewed as penetration depth of diffusible hydrogen into the bulk material. Figure 4 presents the absolute values of the dimensions of this equipotential area obtained via SKP measurement versus time. As it was already observable in the recorded potential maps, described above, movement of hydrogen into the material is not uniform in $x$ - and $y$-direction, as absolute values for diffusion length in $y$-direction are clearly lower than lengths of diffusion path in $x$-direction. However,

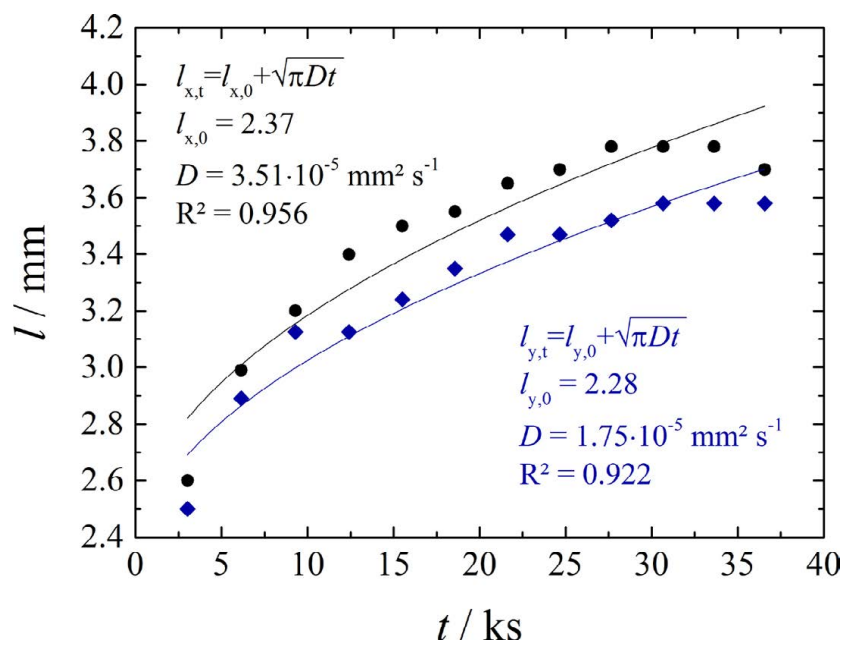

Fig. 4. Determination of hydrogen diffusion coefficient $D$ in $x$ and $y$-direction from lengths of major $\left(l_{\mathrm{x}}\right)$ and minor $\left(l_{\mathrm{y}}\right)$ axis of ellipse describing equipotential area at $0.0 \mathrm{~V}$ (SHE). (Online version in color.) 
the overall progression of the curves behaves similarly with a larger slope in the beginning and a flattening at the end of the regarded time frame. Both curves can be fitted with the following equation, which is an approximation of the penetration depths of the diffusing species, derived from Fick's law: $:^{31)}$

$$
l_{X, t}=l_{X, 0}+\sqrt{\pi D t}
$$

$l_{X, t}$ represents the length of the diffusion path in $x$ - or $y$-direction, $l_{X, 0}$ the initial dimension of the equipotential area directly after finishing hydrogen loading at $t_{0}$ and $D$ is the hydrogen diffusion coefficient. Values for $l_{X, 0}$ and $D$ are obtained by fitting of the experimental data.

Results for $D$ in both regarded directions are located in the same order of magnitude and in the same range as determined via electrochemical hydrogen permeation experiment, but differ in the sense that the value for $D$, calculated for $x$-direction $\left(3.51 \times 10^{-7} \mathrm{~cm}^{2} \mathrm{~s}^{-1}\right)$ is twice as large as in $y$-direction $\left(1.75 \times 10^{-7} \mathrm{~cm}^{2} \mathrm{~s}^{-1}\right)$. This observation can be associated with the rolling process, to which the material was subjected in the course of fabrication. Cold rolling is known to induce a large number of dislocations into the material, influencing hydrogen permeability. ${ }^{32)}$ The sample is oriented on the SKP sample table in a way that rolling direction coincides with $y$-direction of the measurement. It can be therefore concluded that $D$ is larger, when measured orthogonal to the rolling direction as compared to measured parallel.

The performed SKP potential mapping of the hydrogen loaded steel sample allows not only investigating evolutions of equipotential areas, but also of potential minima $\left(\mathrm{CPD}_{\min }\right)$, which is describing the maximum hydrogen concentration, shown in Fig. 5. During the first $10 \mathrm{~h}$, the potential is almost linearly increasing before it reaches a plateau. This behavior can be, again, explained by the Nernst Eq. (1). As already mentioned, $\mathrm{Fe} / \mathrm{Fe}^{2+}$ redox couple present during the first measurement cycles is readily loosing influence on the recorded CPD and replaced by the increasing contribu-

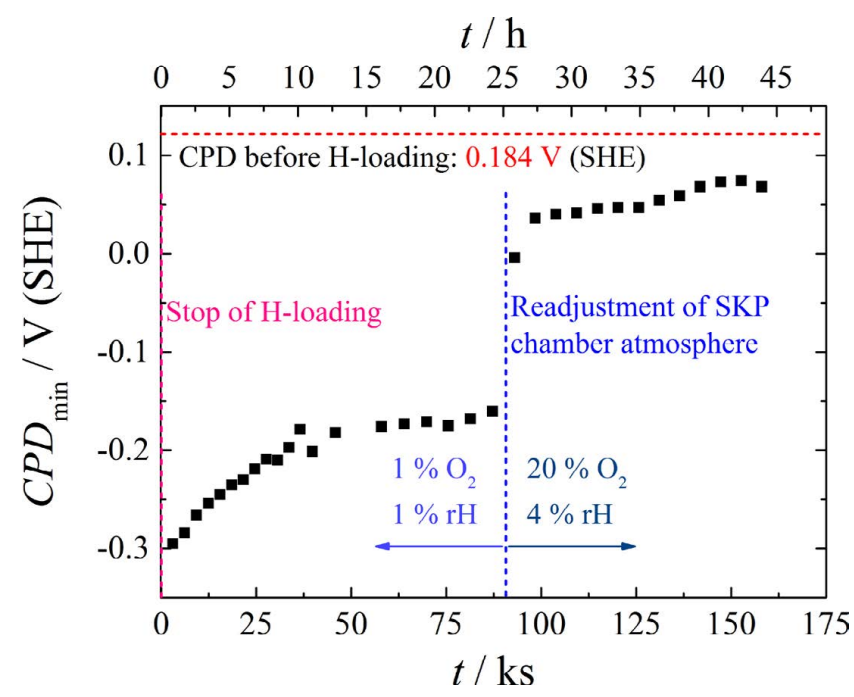

Fig. 5. Measured CPD minima $\left(\mathrm{CPD}_{\min }\right)$ plotted versus time, depicting hydrogen unloading mechanism as well as influence of atmospheric composition on return of measured potential to its initial value before hydrogen charging. (Online version in color.) tion of $\mathrm{Fe}^{2+} / \mathrm{Fe}^{3+}$ redox system. Taking into account hydrogen loaded into the steel sample, two competing reactions are decisive for the course of $\mathrm{CPD}_{\min }$ : on the one hand oxide re-formation proceeds consuming residual oxygen from the atmosphere causing an increase in CPD: ${ }^{23,28,33)}$

$$
\begin{array}{r}
\mathrm{Fe} \rightarrow \mathrm{Fe}^{2+}+2 \mathrm{e}^{-} \ldots \ldots . \\
\mathrm{Fe}^{2+} \rightarrow \mathrm{Fe}^{3+}+\mathrm{e}^{-} \ldots \ldots . \\
1 / 2 \mathrm{O}_{2}+2 \mathrm{H}^{+}+2 \mathrm{e}^{-} \rightarrow \mathrm{H}_{2} \mathrm{O}
\end{array}
$$

On the other hand $\mathrm{Fe}^{2+} / \mathrm{Fe}^{3+}$-ratio is affected by reduction of $\mathrm{Fe}^{3+}$ to $\mathrm{Fe}^{2+}$ with absorbed hydrogen $\left(\mathrm{H}_{\mathrm{ab}}\right)$ :

$$
\begin{gathered}
\mathrm{H}_{\mathrm{ab}} \rightarrow \mathrm{H}^{+}+\mathrm{e}^{-} . \\
\mathrm{Fe}^{3+}+\mathrm{e}^{-} \rightarrow \mathrm{Fe}^{2+}
\end{gathered}
$$

While oxidation reaction of $\mathrm{Fe}^{2+}$ resulting in $\mathrm{Fe}^{3+}$ is occurring at the surface of the sample, reduction of $\mathrm{Fe}^{3+}$ to $\mathrm{Fe}^{2+}$ with absorbed hydrogen as reducing agent is proceeding at the metal-oxide interface. Protons, which are formed in this reaction, are transported through the oxide layer in order to react with atmospheric oxygen, forming water at the sample surface (5). As the SKP is a highly surface sensitive technique, reactions occurring at the outermost layers of the sample will have dominant influence on recorded CPD. ${ }^{34)}$ However, as residual oxygen surrounding the sample is consumed by oxidation reaction of $\mathrm{Fe}^{2+}$ (Eq. (4)), further oxide growth is limited. Finally, the two competing reactions of $\mathrm{Fe}^{2+}$ oxidation (Eqs. (4), (5)) and $\mathrm{Fe}^{3+}$ reduction (Eqs. (6), (7)) end up in equilibrium resulting in a plateau after 11 measurement cycles. Moreover, formation of a plateau is additionally arising from logarithmic dependency on the concentration ratio of oxidized and reduced species shown in Eq. (1). ${ }^{28)}$

After $25 \mathrm{~h}$ and a readjustment of the atmospheric composition in the SKP chamber by introducing oxygen until a concentration of $20 \mathrm{vol} \%$ is reached, a sharp rise in $\mathrm{CPD}_{\min }$ can be observed.

This abrupt rise in measured CPD of hydrogen loaded specimen was also observed by Williams et al. for pure iron. ${ }^{23)}$ By increasing the oxygen content, the iron oxidation reaction (Eq. (4)) is promoted leading to a shift of the $\mathrm{Fe}^{3+} / \mathrm{Fe}^{2+}$-ratio to higher values and an increase in potential, as already concluded from the Nernst equation (Eq. (1)). The reaction of hydrogen with $\mathrm{Fe}^{3+}$ to form $\mathrm{Fe}^{2+}$ (Eq. (7)), which is then re-oxidized by atmospheric oxygen (Eq. (4)), is again affecting this ratio in similar manner as described before. Interestingly, $\mathrm{CPD}_{\min }$ values reach a plateau shortly after readjusting the chamber atmosphere and the potential is not adapting its initial value, even after $45 \mathrm{~h}$. It can be assumed, and similar conclusion was also drawn by Williams et al. in case of iron ${ }^{23)}$ and by Manolatos et al. for electrochemical permeation measurements on steel, ${ }^{35)}$ that the oxide layer on the sample surface is acting as barrier for hydrogen decelerating its escape from the metal specimen. It can be assumed that even at the very last SKP measurement cycle, hydrogen is still present in the sample.

Until today this method is not applicable to galvanized material since the hydrogen overvoltage is too high and the solubility in the zinc is too low, but an extension of the 
application to other materials such as press hardened materials ${ }^{36)}$ maybe realized after an effective coating removal.

\section{Conclusions}

- Local hydrogen charging of steel is possible using a 3D printed droplet cell.

- Scanning Kelvin probe allows detecting, locally monitoring and visualizing the hydrogen concentration in the surface.

- Hydrogen diffusion is clearly rolling direction dependent resulting in a roughly doubled diffusion speed.

\section{Acknowledgement}

Financial support of the Austrian Research Promotion Agency (FFG) within the COMET framework and financial support of Lower Austria is appreciated. The financial support by the Austrian Federal Ministry of Science, Research and Economy and the National Foundation for Research, Technology and Development through the Christian Doppler Laboratory for Combinatorial Oxide Chemistry (COMBOX) is gratefully acknowledged. The authors gratefully thank the voestalpine for the support.

\section{REFERENCES}

1) S. Frappart, A. Oudriss, X. Feaugas, J. Creus, J. Bouhattate, F. Thébault, L. Delattre and H. Marchebois: Scr. Mater., 65 (2011), 859.

2) M. Wang, E. Akiyama and K. Tsuzaki: Corros. Sci., 49 (2007), 4081.

3) F. G. Wei and K. Tsuzaki: Metall. Mater. Trans., 37 (2006), 331.

4) G. Katano, K. Ueyama and M. Mori: J. Mater. Sci., 36 (2001), 2277.

5) M. A. V. Devanathan and Z. Stachurski: Proc. Roy. Soc. A, 270 (1962), 90.

6) N. Boes and H. Züchner: J. Less-Common Met., 49 (1976), 223.

7) T.-H. Yang and S.-I. Pyun: Electrochim. Acta, 41 (1996), 843.

8) T. Zakroczymski: Electrochim. Acta, 51 (2006), 2261.

9) J. Ovejero-Garcia: J. Mater. Sci., 20 (1985), 2623.
10) T. Ohmisawa, S. Uchiyama and M. Nagumo: J. Alloy Compd., 356-357 (2003), 290.

11) J. A. Ronevich, J. G. Speer, G. Krauss and D. K. Matlock; Metallogr. Microstr. Anal., 1 (2012), 79.

12) K. Ichitani, S. Kuramoto and M. Kanno: Corros. Sci., 45 (2003), 1227.

13) K. Ichitani, M. Kanno and S. Kuramoto: ISIJ Int., 43 (2003), 496.

14) M. Koyama, E. Akiyama, T. Sawaguchi, K. Ogawa, I. V. Kireeva, Y. I. Chumlyakov and K. Tsuzaki: Corros. Sci., 75 (2013), 345.

15) G. Schimo, A. M. Kreuzer and A. W. Hassel: Phys. Status Solidi A, 212 (2015), 1202.

16) A. Nishimoto, M. Koyama, S. Yamato, Y. Oda, T. Awane and H. Noguchi: ISIJ Int., 55 (2015), 335.

17) N. Saintier, T. Awane, J. M. Olive, S. Matsuoka and Y. Murakami: Int. J. Hydrogen Energ., 36 (2011), 8630.

18) K. Takai, J. Seki and Y. Homma: Mater. Trans. JIM, 36 (1995), 1134.

19) A. M. Brass, J. Chene and A. Boutry-Forveille: Corros. Sci., 38 (1996), 569.

20) C. Senöz, S. Evers, M. Stratmann and M. Rohwerder: Electrochem. Commun., 13 (2011), 1542.

21) S. Evers and M. Rohwerder: Electrochem. Commun., 24 (2012), 85.

22) S. Evers, C. Senöz and M. Rohwerder: Sci. Technol. Adv. Mater., 14 (2013), 014201.

23) G. Williams, H. N. McMurray and R. C. Newman: Electrochem. Commun., 27 (2013), 144.

24) S. Evers, C. Senöz and M. Rohwerder: Electrochim. Acta, 110 (2013), 534.

25) R. F. Schaller and J. R. Scully: Electrochem. Commun., 40 (2014), 42.

26) M. Rohwerder and F. Turcu: Electrochim. Acta, 53 (2007), 290.

27) G. Schimo, W. Burgstaller and A. W. Hassel: Electrochem. Commun., 60 (2015), 208.

28) M. Krasemann, H. Streckel, K. Hoffmann, H. J. Grabke and M. Stratmann: Electrochem. Soc. Proc., 97 (1997), 207.

29) M. Stratmann and H. Streckel: Corros. Sci., 30 (1990), 681.

30) M. Stratmann and H. Streckel: Corros. Sci., 30 (1990), 697.

31) J. Crank: The mathematics of Diffusion, Clarendon Press, Oxford, (1975), 37.

32) T. P. Radhakrishnan and L. L. Shreir: Electrochim. Acta, 12 (1967), 889.

33) M. Stratmann and K. Hoffmann: Corros. Sci., 29 (1989), 1329.

34) A. Nazarov and D. Thierry: Electrochim. Acta, 52 (2007), 7689.

35) P. Manolatos, M. Jerome, C. Duret-Thuali and J. Le Coze: Corros. Sci., 37 (1995), 1773.

36) R. Autengruber, G. Luckeneder and A. W. Hassel: Corros. Sci., 63 (2012), 12. 